\title{
Letter Forms as Communicative Urban Artifacts for Social Narratives
}

\section{Muhammad Nafisur Rahman}

Doctoral Student

School of Architecture

and Interior Design,

College of Design, Architecture,

Art, and Planning

University of Cincinnati

rahmanmd@mail.uc.edu

\section{Vikas Mehta, Ph.D.}

Associate Professor

Fruth/Gemini Chair,

School of Planning,

College of Design, Architecture,

Art, and Planning

University of Cincinnati

vikas.mehta@uc.edu

\section{INTRODUCTION}

Words, type and letters - as signs and artifacts - have an immense potential to convey meaning in the urban environment. Letterforms are the 'architecture of language' (Baines and Haslam, 2005) - they build narratives, and create inquisitive interpretive spaces through which the reader experiences meaning. Typography and letterforms can be perceived and defined in two ways-functional (legibility) and visual (formal). The utilitarian domain of typography is a prerequisite for effective communication, but letterforms have also been an unending quest for designers to explore and qualify various other more ephemeral dimensions of communication. Unique to letterforms is the distinctive manner in which they can be used to occupy space, convey characteristics, portray personality and physique, and situate dimensionally or even be associated with a variety of emotions. Type is an art form, providing immense pleasure to the everyday observer, reader and speculator.

\section{LETTERFORMS IN HISTORY}

The art and conception of letterform can be traced back to ancient times where art form and communication co-existed in Egyptian hieroglyphs (Jean, 1992). According to Jean, "the word 'hieroglyphs' itself stands for the pictograms and characters used for writing and etymologically, it combines the Greek word 'hieros' meaning "sacred" and 'gluphein', "to engrave" (p. 27). While Trajan capitals in the Roman Empire were laboriously carved, the famous and skillfully executed inscriptions (Diringer, 1977) were glorifying the reign of Emperor Trajan with urban messages to the masses - connecting and elevating the urban art to monumental proportions. After Egyptian hieroglyphs, this is perhaps one of the most recognized point of departure of urban typography on building surfaces in an urban environment.

\section{Abstract /}

Type is a meaningful and perhaps most recognizable and vital urban element of communication. Type is also an art form, providing immense pleasure to the everyday observer, reader, and speculator. The art and conception of letterform can be traced back to ancient Egyptian times where the duality in art form and communications co-existed in hieroglyphs. Today, designers use the monumental landscape of environmental typography in urban spaces for legible semantics, to instigate brand expressions, and to create commercial narratives by employing scale, wit, materiality and evoking more scopes of meaning and spectacle. But words, type and letters - as signs and artifacts - have an immense potential to convey meaning in the urban environment. In this paper, we explore how typographic expression at the urban scale can be applied as a communicative tool in society to express and translate social messages. In the first phase, using urban typography - through its legibility, form, character, and scale - we propose a powerful graphic vocabulary to articulate complex social issues and social narratives of the community in Cincinnati, $\mathrm{OH}$. In the second phase of the project, we plan to engage the residents of individual neighborhoods and conduct workshops to generate and collect social narratives. The process is intended to make residents think critically about their issues and ownership. By using large scale typography, we project the social issues, create narratives and persuasively engage the people of one neighborhood in the city to communicate with those of other neighborhoods.

\section{Keywords /}

urban communication, social issues, public art, community messages, letterforms, 


\section{CONTEMPORARY USE OF LETTERFORMS}

Huerta (2011), claims that it is obligatory for the urbanite to acquaint with visual culture, through which the understanding of the civic becomes easier and provokes us to solve concurrent social problems. According to Huerta:

The city, more than any other environment or landscape, intoxicates us with his letters. Arranged in thousand different ways, in walls, streets, monuments, shops, announcements, the words written and drawn in the skin of the city report his stadiums, his lacks, his sorrows, but especially they us [sic] delight as a legible topography, concluding a certain order of hybrid character: visual and verbal. (p. 25)

The visual landscape is essentially a multifaceted image that is condensed and abstracted in memory as a stock of visual experience (Arnheim, 1969). Quoting Arnheim's understanding of visual landscape, Jakle (1987), states, "Rudolph Arnheim suggested that visual images have 3 primary dimensions: sign, picture and symbols. He narrates that, words on a billboard convey meaning but they themselves do not picture the thing communicated. As simile or metaphor, the thing portrayed, represents some higher order of abstract meaning beyond itself" (p. 16). The complex matrix of visual displays - all those buildings, people, transportation, trees, shops, etc. - demonstrates a hybrid assemblage of visual elements. We also experience the throbbing presence of an array of readable messages, be they on billboards, magazines, or audacious street signs, or name plates of food-carts, buildings, or even as printed typefaces. Every day, we wake up in the morning with type, from our first glimpse at a watch or a toothpaste or breakfast cereal, or even the emails on the phone and text messages. All this happens, in the most diverse range of formats, as we just begin our day. The ubiquity of letters in our everyday life make them a common object, characterizing the potent meaning, context, scale and its symbiotic quest. Its meaning and patterns already have so much penetrated in our everyday psyche that, it is rather impossible to imagine anything without type. We read and react with its personality, form and scale. Words, type and letters as artifacts, categorize and resonate meaning on the urban façade - literal as well as interpretive. They can be found in, on and around urban spaces - sprinkled around throughout the landscape, navigating us through places with legible wayfinding. As a pragmatic tool of communication, designers today use the monumental landscape of environmental typography in urban spaces for legible semantics, to instigate brand expressions, and thoughtful commercial narratives by employing scale, wit, materiality and evoking more scopes of meaning and spectacle. Quoting Victor Hugo and chronologically presenting the Latin Alphabets A-Z (Diar, 1967), states, "So, first comes the house of man, and its construction, then the human body, its build and deformities; then justice, music, the church; war, harvest, geometry; the mountain, nomadic life and secluded life, astronomy, toil and rest; the horse and the snake; the hammer and the urn which - turned over and struck - makes a bell; trees, rivers, roads and finally destiny and God: this is what the alphabet signifies." (Hugo's Travel-diary, 1839). In his famous short essay, "The alphabet is a source", Victor Hugo writes (cited in Diar, 1967):

$A$ is the roof with its rafters and traversebeam, the arch, or it is like two friends who embrace and shake hands. $D$ is the back, and $B$ is a D on a second D, that is a "double back" - the hump; $C$ is the crescent, the moon, $E$ is the foundation of the pillar and the roof - all architecture contained in a single letter. $F$ is the gallows, the fork, $G$ is the horn, $H$ is the façade of a building with its two towers, I is the war machine that projectiles, $J$ is the plough, the horn of plenty, $K$ signifies one of the basic laws of geometry: (the angle of reflection is equal to the angle of incidence), $L$ is the leg and the foot, $M$ is the mountain, or the camp within tents, $N$ is the door, closed with a crossbar, $O$ is the sun, $P$ is the porter carrying a burden, $Q$ is the croup and the tail, $R$ signifies rest, the porter leaning on this stick, $S$ is the snake, $T$ is the hammer, $U$ is the urn, $V$ is the vase (that is why $U$ and $V$ are often confused). I have already said what $Y$ signifies. $X$ signifies crossed swords, combat - who will be victor? Nobody knows - that is why philosophers used " $X$ " to signify fate, and the mathematicians took it for the unknown. $Z$ is the lightning - is God. (p. 2) 
Liberman's (1978) typographic study found Viollet-le-Duc, the French architect and theorist, asserting: "A civilization cannot pretend to possess an art unless that art shall penetrate everywhere - unless it makes its presence felt in the commonest of works" (p. 93).

Dimensional letterforms date back to an age when paper was still a rare element to communicate through. Three-dimensional typography made from stone, metal, wood, or other materials of volume and mass, is well suited for navigation and branding. Large scale typography has been used as a strong element in the visual landscape. The architectonic expressions of large scale typography are impressive and physically much more enduring compared to temporary brochures, scrims, banners, or even posters affixed to similar platforms of communication. Increasingly, dimensional letterforms are emerging as integral components in institutional branding, traditional wayfinding, billboard advertisements, and even in architectural schemes and design of screens (Heller and Illic, 2013). Many outdoor typographic experiences revolve around the perceptual dislocation derived from planting larger format letters, words, and statements in unlikely environments. Letters and words occupy the stage and are physically integrated into the visual landscape to engage visitors with messages, both metaphorically and literally. Here we discuss a few projects with the scale and scope of urban interaction and opportunities of social statements.

A creative work of typographic art by English artist Gordon Young designed in collaboration with Why Not Associates, contains over 160,000 granite letters embedded into 2,200 sq. meters of concrete. The Comedy Carpet, is a pure celebration of British comedy on an extraordinary scale (Figure 1). Gordon asserts the content as a "confection of materials" and installed as a part of regeneration and new sea defenses in a town. He narrates, "I also wanted to create a work with self-consciously high craft standards, as embodied in the

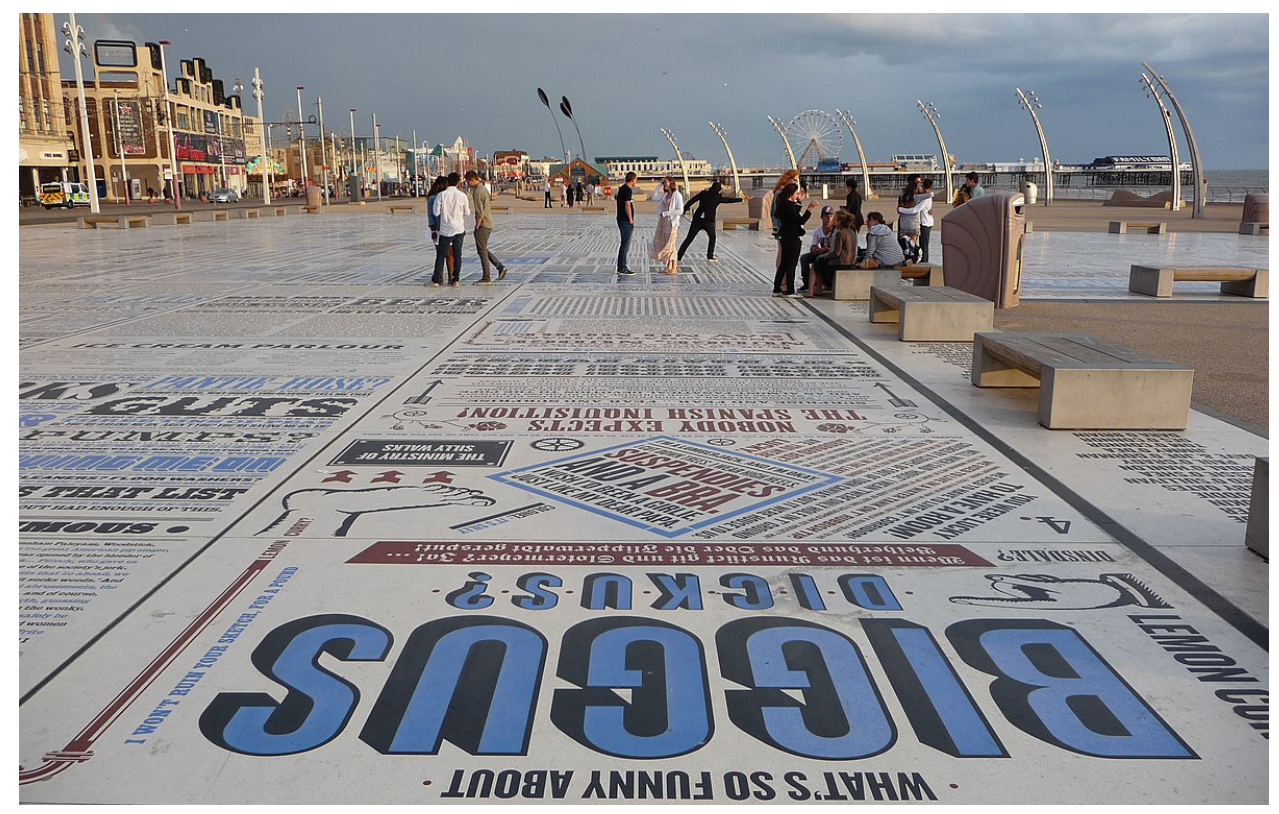

Figure 1 'Comedy Carpet' - a work of art by Gordon Young designed in collaboration with Why Not Associates, in front of Blackpool Tower, UK.

Photo courtesy @ Immanuel Giel (cc-by-sa/3.0) 
Figure 2 Stephen Powers. "A Love Letter to the City", Brooklyn, New York. Photo credit () Stephen Powers, ESPOs ART WORLD
Figure 3 Stephen Powers. "A Love Letter to the City", Brooklyn, New York. Photo credit (c) Stephen Powers, ESPOs ART WORLD town's historic architecture. I chose a carpet because I felt the town needed something very posh in its built environment and I didn't want an area used for comedy to be a run-of-the-mill paving area. And most people who buy and fit a carpet try to look after it." This unique collaborative project engages on a very personal level, through familiar wit and humor, with a diverse yet regular audience (Heller and Ilic, 2014, p. 51). At the same time, 'social congregation', 'personal interpretation' and 'urban conversation' become spontaneous.

'Forever begins when you say yes', at first glimpse seems like nothing more than a corporate advertisement. Then suddenly it becomes something dimensional, romantic, and more enigmatic - a hand-painted love letter at monumental billboard-scale by designer Stephens Powers (Figure 2). With the help of his partner in crime, Dave Villorente, a prolific New York based graffiti artist in the bustling Brooklyn area of New York, Powers transformed the bland surfaces of Macy's garage near Fulton Mall with a series of personal messages in a conversation with someone. The work, thus, resurfaces the voice of the common man in a community and projects it as a legible artifact beyond just a tag of typographic art. Words like "Meet me downtown for a few," with a block-long poem below featuring the words "ninety-nine", over and over again, in tribute to the three 99-cent stores that run the length of the block (Heller and Ilic, 2014). The vernacular characterization and valiant use of enormous scale of signage patterns are intertwined with connecting the

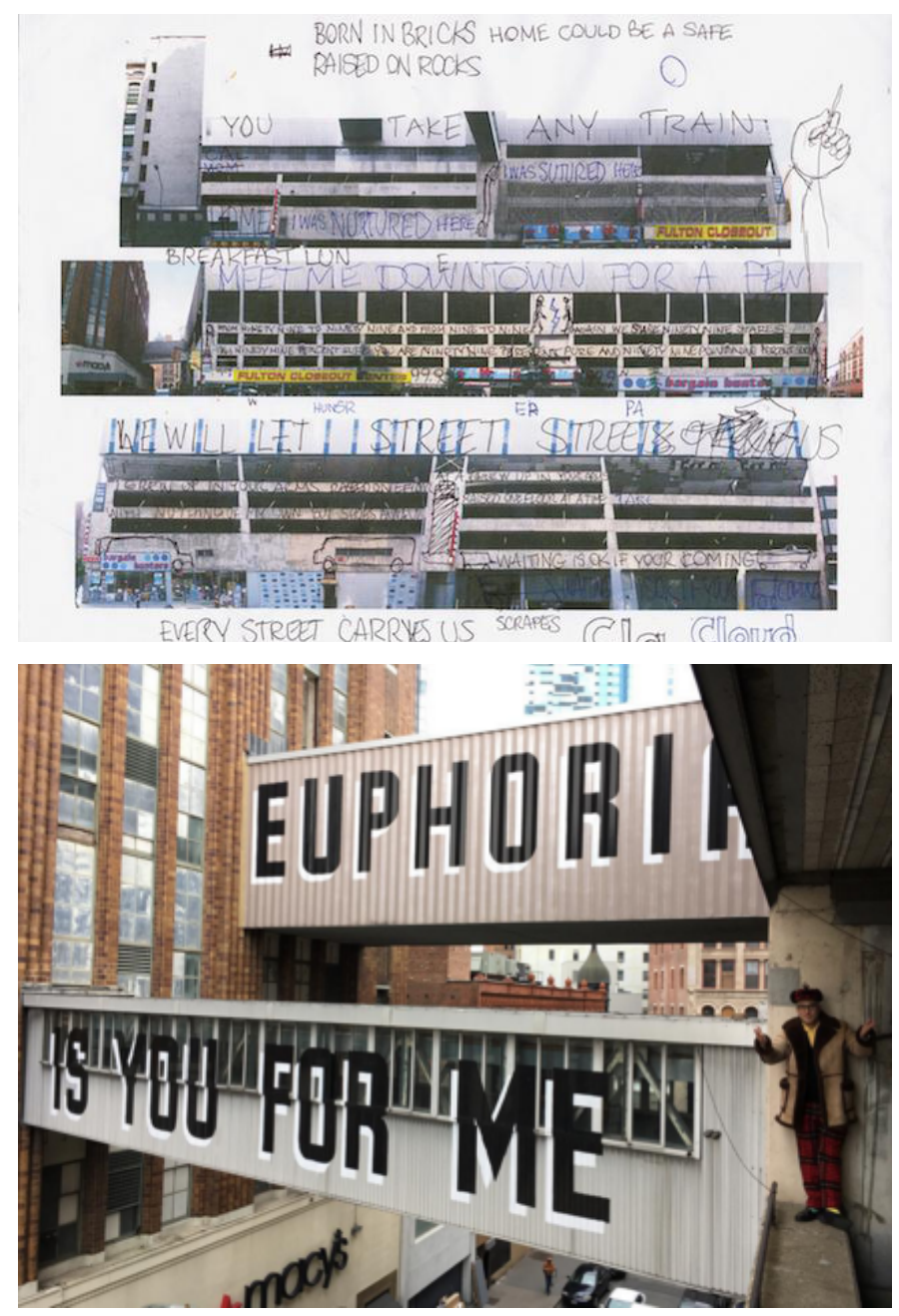




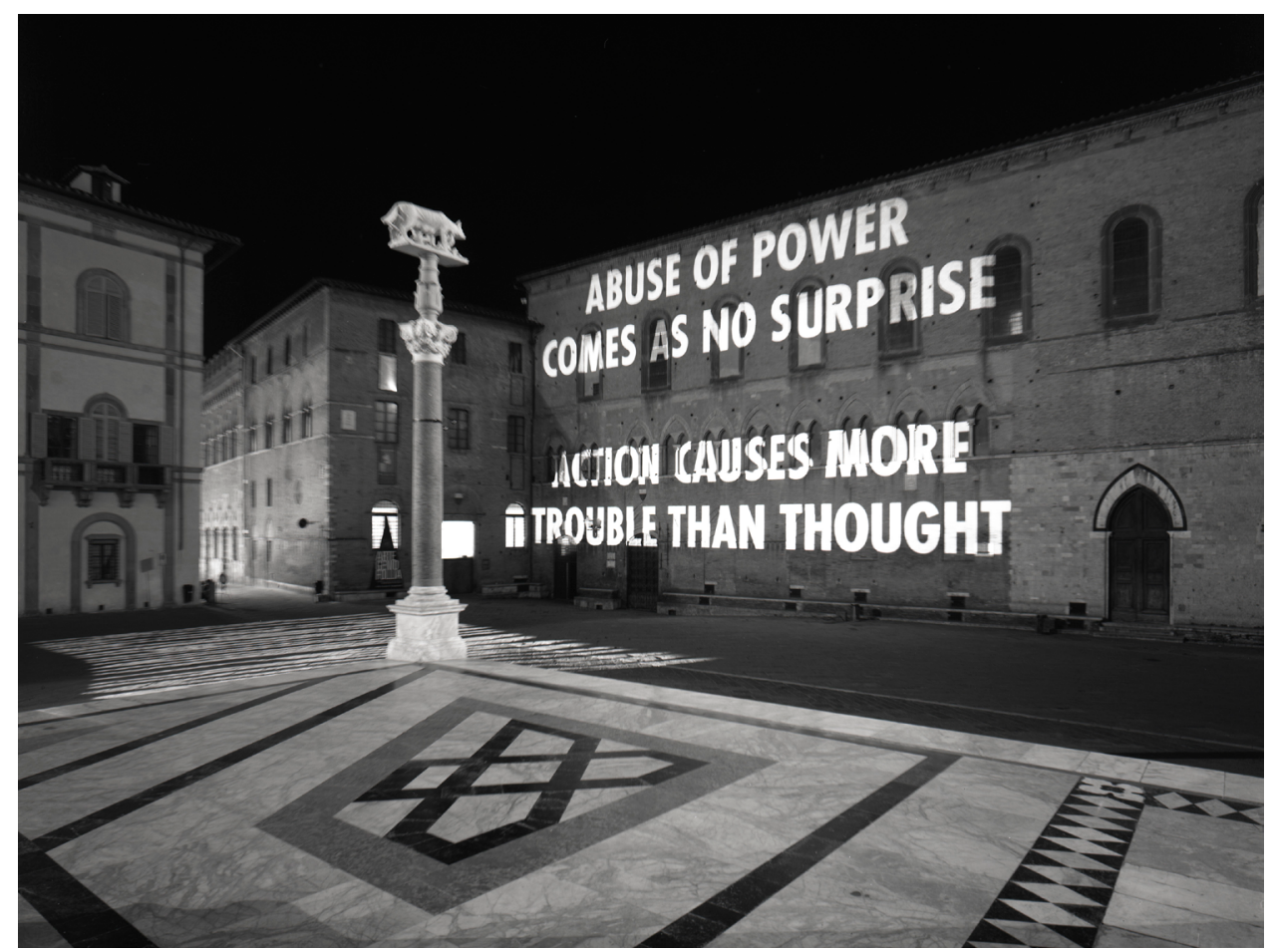

personal voice in an urban landscape instantly evoking urban storytelling, hints of a 'strong persona of the neighborhood', and a quality of human scale (Figure 3). Everyday conversations, contextual and malleable memories along with a "vivid first-person account of growing up in Brooklyn in the 1980s and '90s by Powers" (Powers, 2014, p. 116) instantly connect the context and construes gentrification through design.

Jenny Holzer ${ }^{1}$, searches for new ways to make urban commentary an implicit part of visual objects. She plays with typography in mega-installation art employing three-dimensional structures in urban environments. Instead of using print and working in gallery spaces, she uses an identical yet robust sans serif typeface that reads clearly and boldly from an urban distance (Figure 4). In this case, Holzer must have considered how the type will lay onto the exterior of a building, leaving some of the design to the nature of the building's form. Huge words and numerals outside the buildings and other structures resonate for those who see, intersect, and interact with them. Holzer's urban projections manifest theatrical flair, initiate conversations and arguments among the audiences, and through this endeavor she resurfaces text as a hybrid medium and the public space as an ideal platform. Holzer's projects openly challenge social norms and political structures. Her words are all profound, silent yet active they enlighten viewers with compassion and dignity while reiterating a pristine love for the beauty of large type. Words construct a robust existence in the urban environment and exult the mode of communication.

Making a social statement and to visualize the death of industrial Chicago, designer BJ Krivanek used 28 identical vertical wooden posts that were
Figure 4 For Siena, 2009. Light projection. Santa Maria della Scala, Piazza Duomo, Siena, Italy. Text: Truisms

(C) 2017 Jenny Holzer, member Artists Rights Society (ARS), New York/ / Art Resource, NY / Photo: Attilio Maranzano

For more than thirty-five years, Jenny Holzer, an American neo-conceptual artist, has presented her astringent ideas, arguments, and sorrows in public places Holzer declares in one of her interviews that, "I show what I can with words in light and motion in a chosen place, and when I envelop the time needed, the space around, the noise, smells, the people looking at one another and everything before them, I have given what I know."

(http://projects.jennyholzer.com/biography) 
painted dark creosote black to create a public design project, as a constellation of thoughts, experimental abstractions, and interpretation of the voices of the working-class families. Here, intelligently implemented typographic treatment unfolds a designed duality. Sited in front of Chicago's massive, unoccupied Brach's factory structure across the street, all the rectangular posts have job titles inscribed on the east and west faces - while the north and south sides are inscribed with descriptive words that the workers use to explain their job experience. The statements on the signs come from actual people that Krivanek and his staff interviewed through a handful of the social-service agencies in Austin and Oak Park. Such a simple artwork project on a vacant lot booms the powerful meaning of words in volumes, installing 'type as artifacts' to motivate the neighborhood in a compassionate way. An inherent duality reflects both positive and negative connotations of perceptions, creating an interplay of conditions placing individual voice of a "repairman", "office-manager", "machinist" with "unappreciated", "violated", "under-paid" with "outspoken", "capable" and "trustworthy," for instance. The ordered placement of the posts in a rectangular configuration can be read as a "societal narrative" in a community, or a graveyard to connote the long-vanished industrial Chicago. Social issues are communicated as a delicate manner using the interplay of light, intelligent orientation, and richness of context.

In the everyday city, designers regularly contribute to the privatization, commodification, and sanitization of the public realm by strategically establishing order and consistency through environmental communication that often fails to fulfill their intended use and, most importantly, to generate solutions that are sensitive to the cultural identity, social needs and values of communities (Cue, 2014). Yet, as the examples discussed above show, some designers have embraced deeper social content to better portray the complexity and richness of places. Urban typography, dimensional letterforms and words-particularly because of their dimensional presence-can be a direct and interactive mode of social communication. Subjective interpretation from the everyday urban audience on the streets can impart awareness, interaction, and values. Thus, apart from branding, navigation or advertisements, and using the influence of the visual narrative, urban typography can be used as a powerful tool to project a social voice in the urban milieu. The city presents itself to us full of messages, of elements that can turn out to be very attractive if we observe them from new, interdisciplinary, suggestive, or creative standpoints. Urban typography creates opportunities for curious interactions, complex synergy and public activity. Environmental communication of typography can play a vital role in determining the use of public space through the design of artifacts that connect users to a physical environment and assign meanings to spaces.

\section{CINCINNATI SOCIAL NARRATIVES}

Using urban typography-through its legibility, form, character, and scale-we propose a powerful graphic vocabulary to articulate complex social issues and social narratives of the community in Cincinnati, $\mathrm{OH}$. In this paper, we explore how typographic expression at the urban scale can be applied as a communicative tool in society to express and translate social messages. Our core interest is to investigate how we can deliver urban communication regarding social issues in Cincinnati using urban letterforms as social artifacts. We propose a communication strategy at the urban scale and one at the neighborhood scale. This project is conceived, designed and supported by the Communication in the Urban Environment (CUE) initiative, a research platform in the College of Design, Architecture, Art and Planning (DAAP) at the University of Cincinnati.

\section{THE URBAN DIALOGUE}

Researching the social history of Cincinnati, we find that the city has a prolonged history of social issues including racial segregation, poor public health, high child mortality, unemployment and numerous other societal problems (Maloney and Auffrey, 2013). Cincinnati is divided into several diverse communities, where the social characteristics and needs of these communities vary drastically, and often draw stark boundaries between neighborhoods. Yet, there are some common spaces, such as the century old park system or the newly implemented street car route, that the city residents collectively identify with. We use these common spaces, in this case the streetcar transit stops, as the places of urban communication 
of pressing social messages. Using demographic information from census, local health data, and other sources, we show how letterforms and types in such collective public spaces have the potential to create a dialogue between people of different neighborhoods and communities. Our project is aimed at creating conditions where neighborhood residents can see and simultaneously be seen through the narration of social issues. At this urban
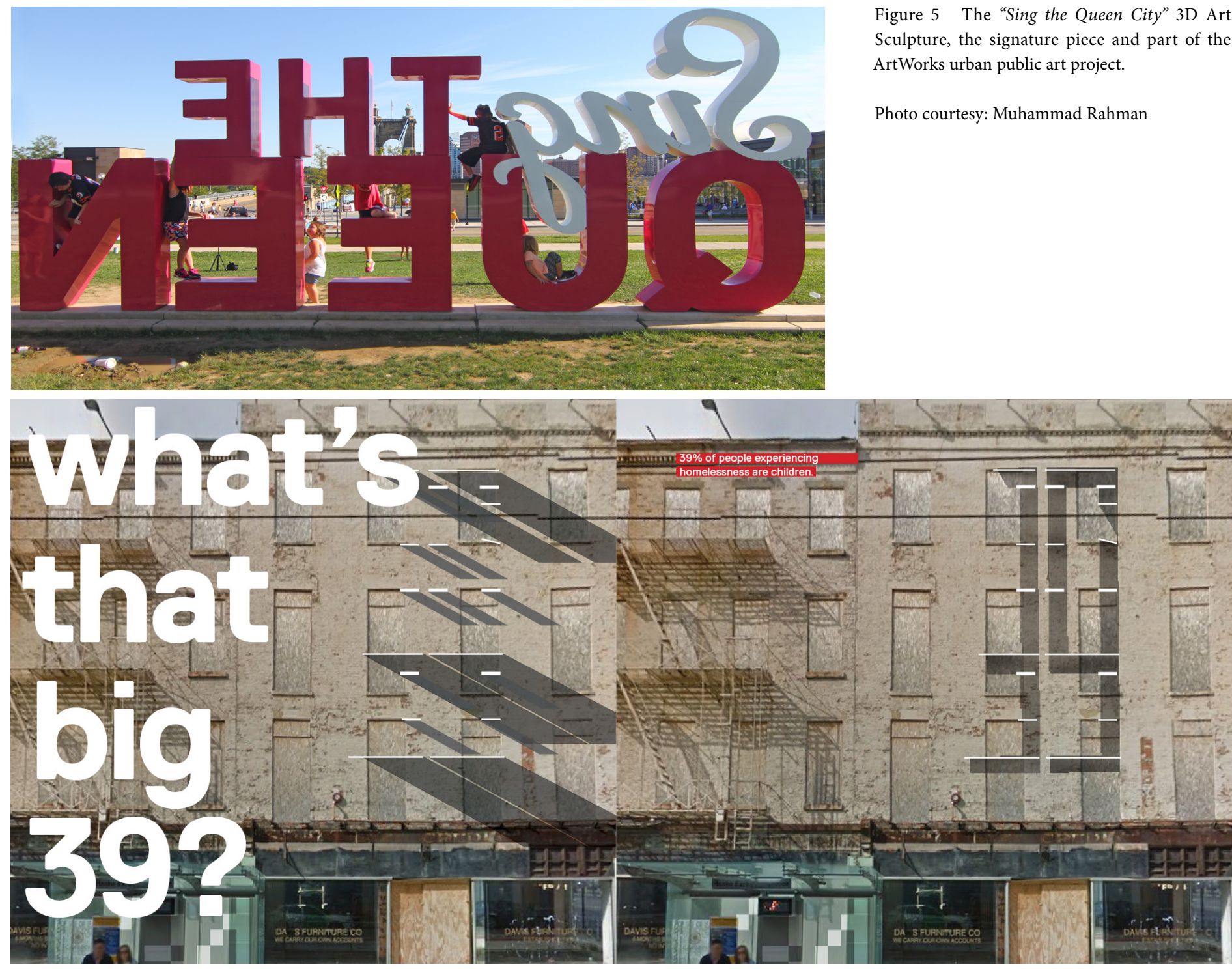

scale, the Cincinnati streetcar connects historical Over-the-Rhine (OTR) and Central Business District (CBD) - two significant neighborhoods in Cincinnati. Various numeric data are proposed as contextual social artifacts and as a designed intervention of potentially effective social communication (Figure 6). This invites interaction by recognizing the existence of the problem in a different way. Large dimensional letterforms visualizing infant mortality, child mortality rate, access to food, crime rates, economic segregation, etc. are proposed to provoke urban communication. According to the City of Cincinnati data, 39\% of people experiencing homelessness are children (Figure 6). The rising rate of this social statistic can be provocative in an urban
Figure 5 The "Sing the Queen City" 3D Art Sculpture, the signature piece and part of the ArtWorks urban public art project.

Photo courtesy: Muhammad Rahman
Figure 6 Proposed visualization of urban artifact for social narrative.

Visualization: Muhammad Rahman 
Figure 7 Proposed visualization of urban artifact for social narrative

Visualization: Muhammad Rahman scale to ignite obvious curiosity (Figure 8 ). In another context, $12 \%$ people are living on the street as homeless and $74 \%$ African-American children are living in poverty in Cincinnati. At an urban scale, we propose an intimate presence of these two quantifiable numbers to provoke reactions. Perhaps some will understand that 12 is lower than 74 and hence, 74 is desirable (Figure 7). This manner of communication pulls the urbanite to engage with the social attributes and explore intersections between the urban condition and social narratives. In this way of social storytelling, the city becomes legible as a social entity and can be viewed through a very different perspective. The design articulates the existing streetcar route, street grids and neighborhood patterns resonating the building patterns, general façade proportions, etc. (Figures 8 and 9).

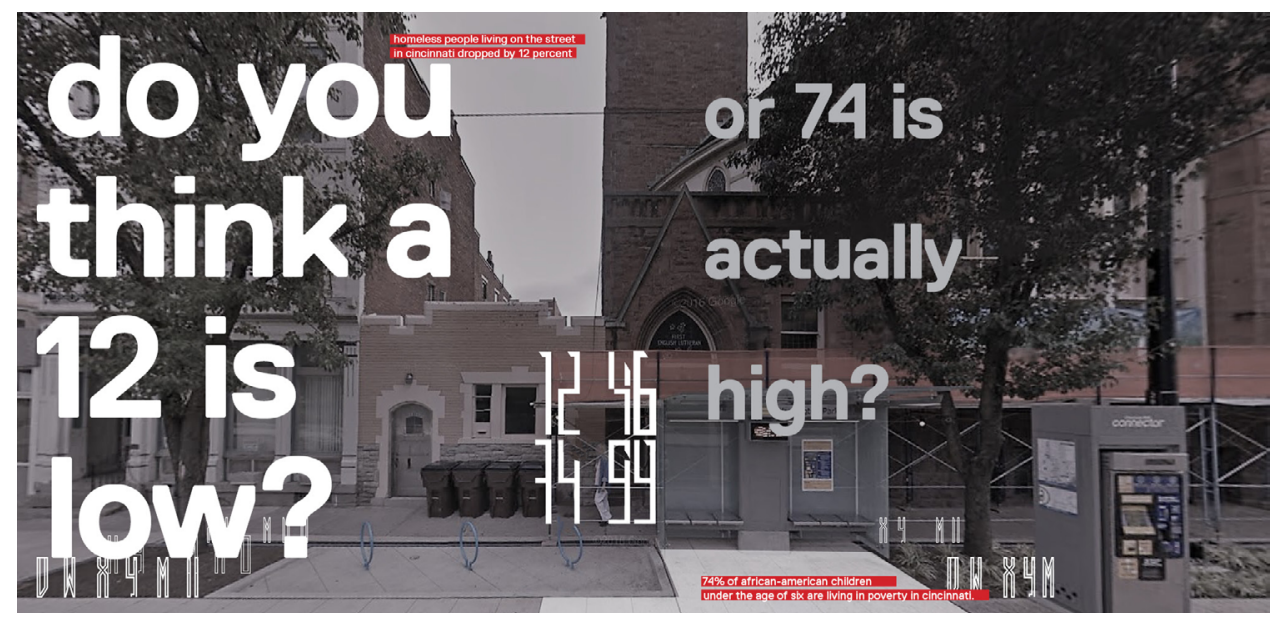

\section{THE NEIGHBORHOOD STORY}

In the second phase of the project, we plan to engage the residents of individual neighborhoods and conduct workshops to generate and collect social narratives. The process is intended to make residents think critically about their issues and ownership. We expect that individual and community voices would interfere, even criticize and most importantly, evoke realization and reinterpretation of the image of Cincinnati - which might also educate and promulgate values to mitigate segregation and social issues in the city. The yearning wishes of a neighborhood would be collected through interviews

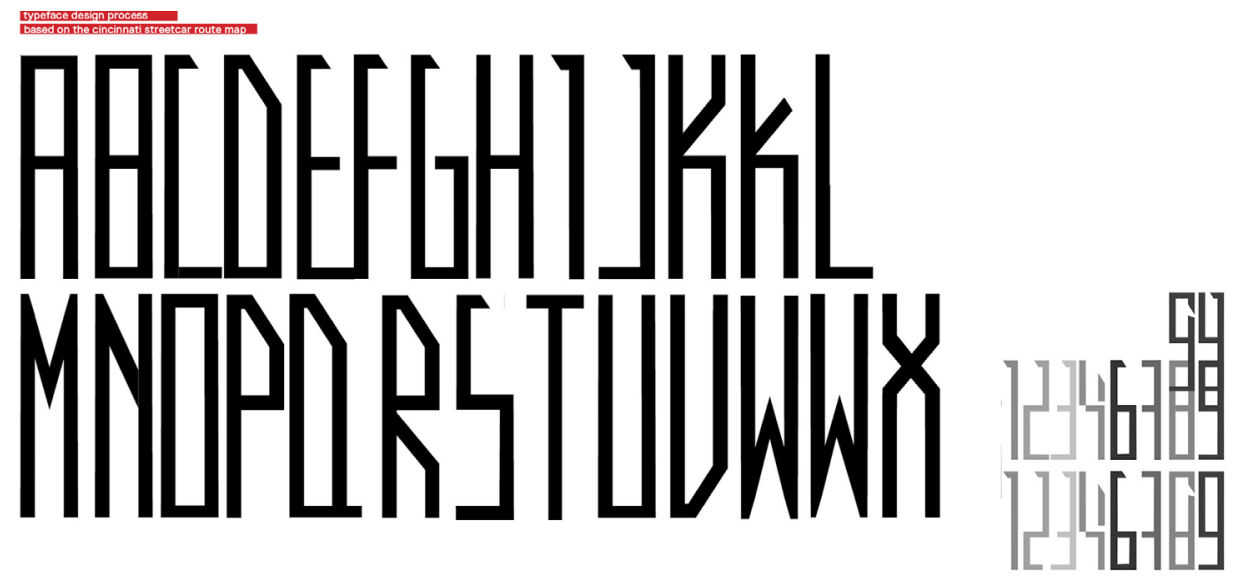

Figure 8 Proposed designed typeface for the project derived from the context. 

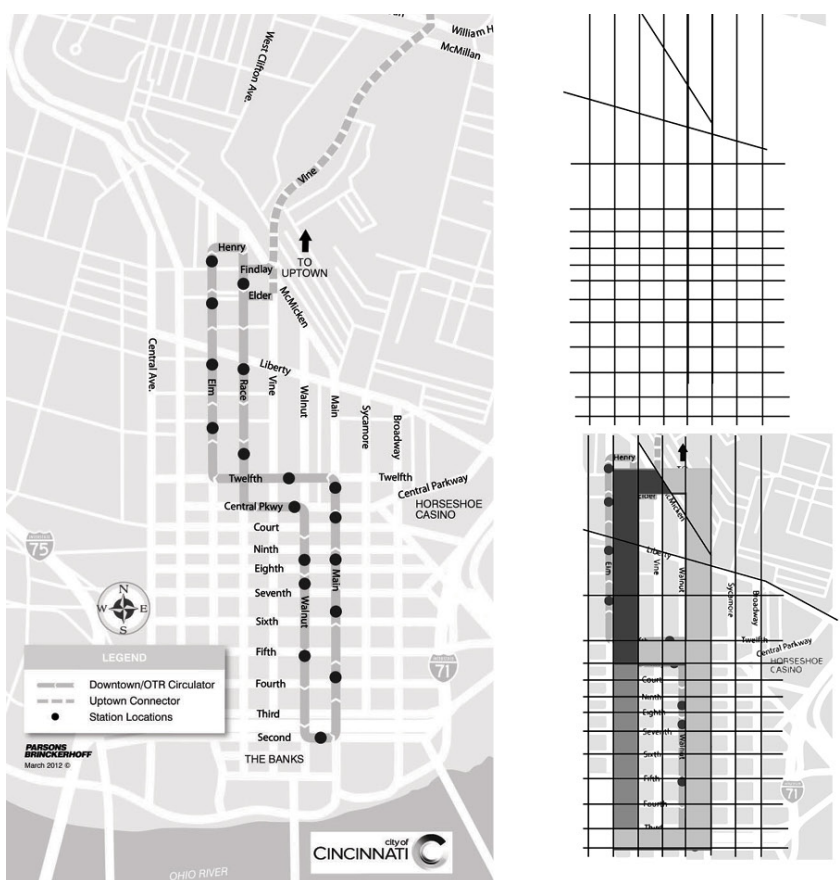

while simultaneously expressing three things: their free desire, their present state of mind and anything they miss. As a volume of narratives collected from the community in the neighborhood, we will start to look at patterns of participations and their wishes. Following that, we will project these expressions of words, choice of desires, or grains of neighborhood identity. The process will include several iterations of various options such as, fabrication of dimensional letterforms, and projecting on a dimensional scale on urban walls in a neighborhood. To define the scope of design, context and limits, codes and permits will be taken into consideration for implementation. The letterform design considers the visual taxonomy of motifs, urban plans, buildings and historical images of neighborhoods in Cincinnati.

\section{IMPLICATIONS FOR CINCINNATI AND OTHER PLACES}

Aside from other physical and social attributes, ubiquitous assemblage and diverse range of type, signage, public art, storefront displays, street-signs, and other signage helps in creating a neighborhood identity. The large letterforms in urban environments interact with the patrimonial fabric of the city. Interpretation of various community and urban context in public space has the ability to become design tools of communication, and celebrate the diverse richness and exquisite values of a neighborhood. This project has several implications for planning. With environmental

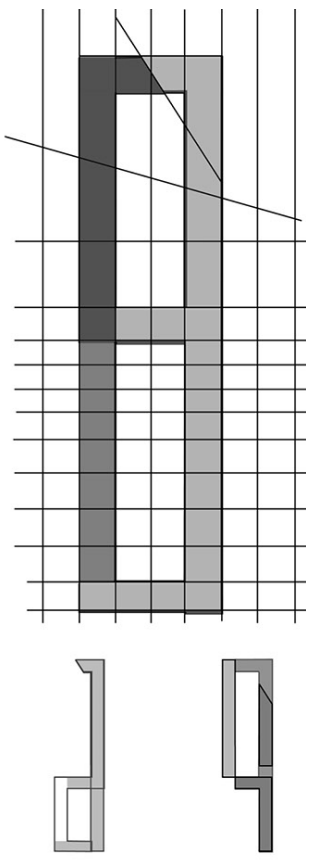

Figure 9 Design process of the proposed designed typeface for the project. communication, as 'social capital' (Cue, 2014), urban typography can play an important role in fostering urban regeneration and signifying educational value (Huerta, 2011), and act as a direct and interactive mode of social communication. Apart from traditional mediums, urban typography has been popularly used as a hybrid tool to influence the visual narrative, and as a vehicle for impact of social voice in the urban milieu (Heller and Ilic, 2013). To address and comprehend diversity, difference and unique identities between neighborhoods, urban typography can communicate a neighborhood's societal aptitude and trigger an urban discourse. 


\section{REFERENCES}

Arnheim, R. (1969). Visual Thinking. Berkley: University of California Press.

Baines, P. and Haslam, A. (2005). Type and Typography. New York: Watson-Guptill Publications. 7.

Carter, R., and Meggs, P. (2002). Typographic Design: Form and Communication. New York: John Wiley \& Sons.

Cue, P. (2014). “On the Wall: Designers as Agents for Change in Environmental Communication. Visible Language Design Research Journal, 48 (2), 71-83.

Diar, C. (1967). Design with Type. New York: University of Toronto Press.

Diringer, D. (1977). A History of Alphabet. Surrey: The Gresham Press.

Drucker, J. (2008). "Letterpress Language: Typography as a Medium for the Visual Representation of Language." Leonardo 41 (1), 66-74.

Gouveia, S., Paula, A., Farias, P. L. and Gatto. P. S. (2009). "Letters and Cities: Reading the Urban Environment with the Help of Perception Theories.", Visual Communication, 8 (3), 339-48.

Heller, S. and Ilic, M. (2013). Lettering Large. New York: Monacelli Press.

Huerta, R. (2011). "City as a museum of letters", City, Culture and Society, 2, 25-33.

Jakle. A (1987). The Visual Elements of Landscape. Amherst: The University of Massachusetts Press.

Jean, G. (1992). Writing the Story of Alphabets and Scripts. New York: Harry Abrams Inc. Publishers.

Lieberman, B. (1978). A Treasury of Typography Book. New York: The Myriad Press.

Lupton, E., and Miller, A. (1996). Design Writing Research. New York: Phaidon Press Inc.

Maloney, M. and Auffrey, C. (2013). The Social Areas of Cincinnati: An Analysis of Social Needs. Cincinnati: Cincinnati Human Relations Commission.

Marshall, G. (2015). “Graphic DNA Project: Tracing Urban Developments through Environmental Letters., International Journal of Interdisciplinary Cultural Studies 9 (1), 1-10.

Power, S. (2014). A Love Letter to the City. New York: Princeton Architectural Press. 